\title{
Revascularization grading in endovascular acute ischemic stroke therapy
}

O.O. Zaidat, MD, MS

M.A. Lazzaro, MD

D.S. Liebeskind, MD

N. Janjua, MD

L. Wechsler, MD

R.G. Nogueira, MD

R.C. Edgell, MD

J.S. Kalia, MD

A. Badruddin, MD

J. English, MD

D. Yavagal, MD

J.F. Kirmani, MD

A.V. Alexandrov, MD

P. Khatri, MD

Correspondence \& reprint requests to Dr. Zaidat: szaidat@mcw.edu

\section{ABSTRACT}

Background: Recanalization and angiographic reperfusion are key elements to successful endovascular and interventional acute ischemic stroke (AIS) therapy. Intravenous recombinant tissue plasminogen activator (rt-PA), the only established revascularization therapy approved by the US Food \& Drug Administration for AIS, may be less effective for large artery occlusion. Thus, there is enthusiasm for endovascular revascularization therapies, which likely provide higher recanalization rates, and trials are ongoing to determine clinical efficacy and compare various methods. It is anticipated that clinical efficacy will be well correlated with revascularization of viable tissue in a timely manner.

Method: Reporting, interpretation, and comparison of the various revascularization grading methods require agreement on measurement criteria, reproducibility, ease of use, and correlation with clinical outcome. These parameters were reviewed by performing a Medline literature search from 1965 to 2011. This review critically evaluates current revascularization grading systems.

Results and Conclusion: The most commonly used revascularization grading methods in AIS interventional therapy trials are the thrombolysis in cerebral ischemia $(\mathrm{TICl}$, pronounced "tissy") and thrombolysis in myocardial ischemia (TIMI) scores. Until further technical and imaging advances can incorporate real-time reliable perfusion studies in the angio-suite to delineate regional perfusion more accurately, the $\mathrm{TICl}$ grading system is the best defined and most widely used scheme. Other grading systems may be used for research and correlation purposes. A new scale that combines primary site occlusion, lesion location, and perfusion should be explored in the future. Neurology ${ }^{\circledR} 2012 ; 79$ (Suppl 1):S110-S116

\section{GLOSSARY}

AIS = acute ischemic stroke; $\mathbf{A O L}=$ arterial occlusive lesion; $\mathbf{A S I T N} / \mathbf{S I R}=$ American Society of Intervention and Therapeutic Neuroradiology/Society of Interventional Radiology; DSA = digital subtraction angiography; ERT = endovascular revascularization therapy; $\mathbf{M C A}=$ middle cerebral artery; $\mathbf{r t - P A}=$ recombinant tissue plasminogen activator; $\mathbf{S V I N}=$ Society of Vascular \& Interventional Neurology; TIBI = thrombolysis in brain ischemia; $\mathbf{T I C I}=$ thrombolysis in cerebral ischemia; TIMI = thrombolysis in myocardial ischemia.

Rapid and safe revascularization leading to good clinical outcome is the goal of acute ischemic stroke (AIS) therapy. Despite extensive investigation, only one therapy has demonstrated efficacy with randomized controlled trial: thrombolysis with intravenous recombinant tissue plasminogen activator (rt-PA). ${ }^{1}$ The efficacy of rt-PA as an emergency treatment for AIS was demonstrated in 1995 , which marked a milestone in stroke care. ${ }^{1}$ Limitations to systemic rt-PA use have led to enthusiasm for alternative methods of revascularization therapy. Endovascular revascularization therapy (ERT) in AIS employs methods including intra-arterial thrombolysis, thromboaspiration, sonothrombolysis, and mechanical thrombectomy. A favorable clinical outcome is the ultimate goal of ERT, and revascularization has been shown to be associated with good clinical outcome in stroke studies. ${ }^{2}$

From the Departments of Neurology (O.O.Z., M.A.L.), Neurosurgery (O.O.Z.), and Radiology (O.O.Z.), Medical College of Wisconsin/Froedtert Hospital, Milwaukee; UCLA Stroke Center (D.S.L.), Los Angeles, CA; Department of Neurology, Asia Pacific Comprehensive Stroke Institute (N.J.), Pahoa, HI; Department of Neurology, University of Pittsburgh Medical Center (L.W.), PA; Emory University (R.G.N.), Atlanta, GA; St. Louis University (R.C.E.), St. Louis, MO; University of Illinois at Chicago/Provena St. Joseph Hospital (A.B. [Daniel M. Soref Clinical Neuroscience Fellow]), Chicago; Department of Neurology, University of California San Francisco (J.E.), San Francisco; University of Miami (D.Y.), Miami, FL;

JFK Neuroscience Center (J.F.K.), Edison, NJ; Comprehensive Stroke Center, University of Alabama Hospital (A.V.A.), Birmingham; and University of Cincinnati (P.K.), Cincinnati, OH.

Go to Neurology.org for full disclosures. Disclosures deemed relevant by the authors, if any, are provided at the end of this article. 
Several nonrandomized trials have evaluated the safety and efficacy of various endovascular approaches, but interpreting and comparing their results is challenging because of heterogeneous trial designs. In particular, a uniform revascularization grading system is lacking. Furthermore, ischemia in acute stroke is extremely complex and perhaps warrants distinction of primary ischemia resulting from a vessel occlusion vs secondary ischemia characterized by collateral blood flow and cerebral oxygen supply that is dependent on other parameters, including arterial blood pressure and arterial oxygen content. ${ }^{3} \mathrm{We}$ review the literature on available methods for measuring cerebrovascular revascularization and emphasize the need for consensus on reporting standards for revascularization. Although revascularization would seem to be only one of the factors important in salvaging tissue at risk, it appears to play a considerable role. In selected patients with AIS, successful recanalization of the thrombotic occlusion is a strong predictor of lower 3-month mortality and favorable functional outcomes. ${ }^{2,4,5}$ Furthermore, successful recanalization has been reported as the main predictor of good outcome among patients treated with mechanical thrombectomy. ${ }^{6}$ In addition, time to revascularization is an independent predictor of good outcome in select patients with AIS. ${ }^{7}$ Although these findings fuel a growing interest in thrombectomy, rigorous clinical trials are needed to better understand the role of endovascular revascularization for optimizing clinical outcomes. This underscores the importance of defining, scoring, and reporting revascularization in AIS studies. ${ }^{8,9}$

REVASCULARIZATION, REPERFUSION, AND RECANALIZATION Revascularization is variably defined in AIS studies as recanalization, which represents restoration of vessel patency at the site of occlusion; angiographic reperfusion, which includes contrast opacification of the distal arterial territory; and a combination of these definitions. The combination of recanalization and reperfusion is the more comprehensive and perhaps most clinically relevant descriptor of revascularization. Recanalization and reperfusion can occur independently of each other, but typically they have considerable overlap. Recanalization does not guarantee angiographic or tissue reperfusion, as the no-reflow phenomenon may pre- clude perfusion of target tissue because of distal branch occlusions, despite restoration of proximal vessel patency.

Reperfusion refers to anterograde perfusion of patent microvasculature supplying the target tissue after recanalization. It is important to note that distal territory may also receive perfusion in a retrograde flow pattern from collateral supply; therefore, angiographic reperfusion distinctly involves perfusion of distal territory in an anterograde manner following recanalization. The collateral supply, providing retrograde filling, is an additional important element of revascularization that has received limited attention in clinical trial reporting.

Recanalization scoring seems to be intuitive, requiring grading of the vessel patency or, in other words, residual clot burden. Reperfusion, on the other hand, involves a more intricate set of parameters including distinguishing anterograde perfusion, quantifying the extent of the vascular bed that is reperfused, and assessing the perfusion time. Collateral supply is also challenging to characterize, in part because of poorly defined parameters for grading and individual variability in the Circle of Willis evaluation amid the endovascular intervention. Agreement on the definition of revascularization is essential for reporting, reproducibility, and comparative interpretation of ERT studies. An optimal grading system would take into consideration all of the latter criteria (table 1).

ANGIOGRAPHIC GRADING SYSTEMS Endovascular revascularization therapy involves digital subtraction angiography (DSA), which offers characterization of blood flow in AIS. Angiography allows evaluation of the occlusion site, potentially the length of the vessel harboring the clot, extent of collateral supply, as well as postintervention characterization of vessel patency, rate of blood flow, reperfusion territory, distal occlusion/embolization, and early venous shunting. Features poorly represented by less-invasive imaging, including spatial and temporal resolution and retrograde flow characterization, are permitted with catheter angiography. These factors are measured to

\footnotetext{
Table $1 \quad$ Criteria for an optimal revascularization scale

- Takes into account both recanalization and reperfusion

- Takes into account cerebral collateral circulations

- Reproducibility: intra- and inter-rater reliability

- Ease of use and application in daily practice, not trialsonly scale

- Comparable results across clinical trials

- Prognostic significance and correlation with clinical outcome
} 
varying degrees in the available angiographic grading scales. Several grading systems have been proposed to characterize angiographic findings in cerebral ischemia. Each scheme shows variable emphasis on the different angiographic aspects that include arterial occlusion, perfusion, lesion location, and collateral flow (table 2). Several of the grading systems have also been shown to be associated with clinical outcome.

Thrombolysis in Myocardial Infarction score. The Thrombolysis in Myocardial Infarction (TIMI) Study Group devised the first angiographic score for reperfusion in acute myocardial infarction. ${ }^{10,11}$ This is a simple angiographic score that has been used in numerous major cardiovascular trials of thrombolytic agents, balloon angioplasty, and stent placement. The TIMI score is graded from 0 to 3 according to angiographic demonstration of blood flow (table 2). The TIMI flow grading system has been useful in predicting outcome for cardiac patients. ${ }^{12}$ In AIS trials, TIMI has been applied in a variable manner and with variable operating definitions to assess recanalization, angiographic reperfusion, or both. ${ }^{13}$ Some applications of the TIMI scale that have been associated with clinical functional outcomes have been demonstrated in studies of intra-arterial thrombolysis for AIS. ${ }^{13,14}$ The variability in the operating manual/grading definition of the TIMI scoring system is the main disadvantage of its use across clinical trials; however, its biggest advantage is its simplicity and familiarity to many stroke neurologists and neurointerventionalists.

Mori reperfusion scale. In 1992, Mori et al. ${ }^{15}$ published a report of intracarotid urokinase injection for acute middle cerebral artery (MCA) occlusion in 22 patients. In the manuscript, the authors described a novel grading scale for reporting cerebral angiographic reperfusion. The Mori scale ranges from 0 to 4 , representing no reperfusion to complete reperfusion (table 2). Whereas the TIMI score of 2 represents partial recanalization, the Mori scale subdivides this into Mori grades 2 and 3, based on reperfusion of the distal arterial territory. Mori grade 2 represents less than $50 \%$ distal flow, and grade 3 represents greater than $50 \%$ distal flow. Subsequent evaluation of the Mori grading system demonstrated association with clinical outcome and suggested that the expanded distinction of reperfusion categories may improve outcome prediction. ${ }^{14}$

Qureshi scale. A new classification scheme proposed by Qureshi ${ }^{16}$ in 2002 is different from other grading schemes in several ways. This scale includes 6 grades that range from 0 to 5 , classifying no occlusion (0) to large-vessel occlusion of the internal carotid artery or basilar artery with no collaterals; thus, higher grades indicate worse angiographic outcomes than lower grades. This scale also is based on the site of arterial occlusion and the presence of collateral pathways. The grading increases in severity according to the size and location of occlusions, starting from smallervessel occlusions (M3, A2, BA branches) to the intermediate-sized M1 segment, to large arteries (internal carotid artery, basilar artery). This scale's strength is in its design to incorporate clinical severity by considering the size of the occluded vessel's vascular territory. However, its complexity may preclude its routine use.

Thrombolysis in Cerebral Infarction scale. With the growth of AIS studies, standards for design and reporting were proposed in 2003 by Higashida et al., including recommendation of the Thrombolysis in Cerebral Infarction (TICI) scale. ${ }^{17}$ This scale is a modified version of the TIMI scale that provides a subcategorization of the second perfusion score into grades $2 \mathrm{~A}$ and $2 \mathrm{~B}$ (table 2). Additionally, the authors also provided explicit definitions for designating each grade that are directly relevant to cerebral vasculature. The TICI grading approach uses contrast filling and clearance time to further stratify the wide range of partial reperfusion that exists between the TIMI grades 1 (minimal reperfusion) and 3 (complete reperfusion). Thus, as with the Mori scale, the TICI scale creates further categories of partial reperfusion, and study of the Mori scale suggests that this is likely to be clinically relevant. ${ }^{14}$ The TICI scale is being used to grade revascularization in the recently stopped IMS-III trial; these results may offer further evaluation of this grading scale.

Arterial Occlusive Lesion score. The Arterial Occlusive Lesion (AOL) scoring system was introduced in the IMS I pilot trial to evaluate recanalization directly. ${ }^{13}$ It focuses solely on the clot burden at the original arterial occlusive site. The AOL system assigns a score from 0 to 3 , which represents the range from no recanalization to complete recanalization with any distal flow (table 2). This method was compared with TIMI reperfusion scoring in the IMS I trial to determine the relationship between recanalization and reperfusion; there was no statistical difference between the two methods of prediction of clinical outcome $(p=0.11)$, although numerically TIMI reperfusion had a higher association. ${ }^{13}$ The agreement between the 2 scales was modest (interscales AOL to TIMI $\kappa$ is 0.30 ; confidence interval, 0.16 to 0.44$).{ }^{13}$ This analysis suggested that recanalization is related to reperfusion, and both may be important in overall clinical outcomes. The AOL score will also be reported in the IMS-III trial results.

Extent of collateral supply. Collateral supply has an important role in sustaining the threatened vascular 
Table 2 Current grading systems for vessel revascularization on cerebral arteriography ${ }^{\mathrm{a}}$

\begin{tabular}{|c|c|c|c|c|}
\hline Grade & TIMI & $\mathrm{TICl}$ and modified $\mathrm{TICl}$ & Mori & AOL \\
\hline 0 & No recanalization & $\begin{array}{l}\text { No perfusion and no anterograde flow beyond the point } \\
\text { of occlusion }\end{array}$ & No reperfusion & $\begin{array}{l}\text { No recanalization of the } \\
\text { primary AOL }\end{array}$ \\
\hline 1 & $\begin{array}{l}\text { Minimal } \\
\text { recanalization }\end{array}$ & $\begin{array}{l}\text { Penetration with minimal perfusion; the contrast material } \\
\text { passes beyond the area of obstruction but fails to } \\
\text { opacify the entire cerebral bed distal to the obstruction } \\
\text { for the duration of the angiographic run }\end{array}$ & Minimal reperfusion & $\begin{array}{l}\text { Complete or partial } \\
\text { recanalization of the } \\
\text { primary occlusive lesion } \\
\text { with no distal flow }\end{array}$ \\
\hline \multirow[t]{2}{*}{2} & $\begin{array}{l}\text { Partial } \\
\text { recanalization }\end{array}$ & $\begin{array}{l}\text { Partial perfusion; the contrast material passes the } \\
\text { obstruction and opacifies the arterial bed distally. } \\
\text { However, the rate of entry of contrast into the vessel } \\
\text { distal to the obstruction or its clearance rate from the } \\
\text { distal bed is perceptibly slower than its entry into or } \\
\text { clearance from comparable areas not perfused by the } \\
\text { previously occluded vessel, e.g., the opposite cerebral } \\
\text { artery or the arterial bed proximal to the obstruction. }\end{array}$ & $\begin{array}{l}\text { Reperfusion of }<50 \% \text { of the } \\
\text { territory of the occluded artery }\end{array}$ & $\begin{array}{l}\text { Incomplete or partial } \\
\text { recanalization of the } \\
\text { primary occlusive lesion } \\
\text { with any distal flow }\end{array}$ \\
\hline & & $\begin{array}{l}2 \mathrm{~A} \text { : Only partial filling }(<2 / 3 \text {, modified }<50 \%) \text { of the } \\
\text { vascular territory is visualized }\end{array}$ & & \\
\hline 4 & No grade 4 & No grade 4 & Complete reperfusion & No grade 4 \\
\hline 5 & No grade 5 & No grade 5 & No grade 5 & No grade 5 \\
\hline Grade & & TIBI Grading Scale & Qureshi Grading Scale & $\begin{array}{l}\text { ASITN/SIR Collateral Flow } \\
\text { Grading Scale }\end{array}$ \\
\hline 0 & & Absent: absent flow & No occlusion & $\begin{array}{l}\text { No collaterals visible to the } \\
\text { ischemic site }\end{array}$ \\
\hline 1 & & $\begin{array}{l}\text { Minimal: systolic spikes of variable velocity and duration } \\
\text { and absent diastolic flow }\end{array}$ & $\begin{array}{l}\text { MCA occlusion (M3 Segment) or } \\
\text { ACA occlusion (A2 or distal } \\
\text { segments) or one basilar or } \\
\text { vertebral branch occlusion }\end{array}$ & $\begin{array}{l}\text { Slow collaterals to the } \\
\text { periphery of the ischemic } \\
\text { site, with persistence of } \\
\text { some of the defect }\end{array}$ \\
\hline 2 & & $\begin{array}{l}\text { Blunted: flattened systolic flow with positive EDV and } \\
\text { pulsatility }\end{array}$ & $\begin{array}{l}\text { MCA occlusion (M2 Segment) or } \\
\text { ACA occlusion (A1 or distal } \\
\text { segments) or two basilar or } \\
\text { vertebral branch occlusions }\end{array}$ & $\begin{array}{l}\text { Rapid collaterals to the } \\
\text { periphery of ischemic site, } \\
\text { with persistence of some of } \\
\text { the defect, and to only a portion } \\
\text { of the ischemic territory }\end{array}$ \\
\hline 3 & & & $\begin{array}{l}\text { 3B: lenticulostriate arteries and } \\
\text { leptomeningeal collateral supply } \\
\text { is not visualized }\end{array}$ & \\
\hline 4 & & $\begin{array}{l}\text { Stenotic: MFV of }>80 \% \text { and velocity difference } \\
\text { of }>30 \%\end{array}$ & $\begin{array}{l}\text { ICA occlusion (collaterals present) } \\
\text { or BA occlusion (partial filling direct } \\
\text { or via collaterals) }\end{array}$ & $\begin{array}{l}\text { Complete and rapid collateral } \\
\text { blood flow to the vascular } \\
\text { bed in the entire ischemic } \\
\text { territory by retrograde } \\
\text { perfusion }\end{array}$ \\
\hline 5 & & Normal: $<30 \%$ MFV difference vs control & $\begin{array}{l}\text { Complete occlusion of the ICA or } \\
\text { BA with no collateral filling }\end{array}$ & No grade 5 \\
\hline
\end{tabular}

Abbreviations: $\mathrm{ACA}=$ anterior cerebral artery; $\mathrm{AOL}=$ arterial occlusion lesion; ASITN/SIR = American Society of Intervention and Therapeutic Neuroradiology/Society of Interventional Radiology; BA = basilar artery; EDV = end diastolic velocity; ICA = internal carotid artery; $\mathrm{MCA}=$ middle cerebral artery; $\mathrm{MFV}=$ mean flow velocity; $\mathrm{TICl}=$ thrombolysis in cerebral infarction; $\mathrm{TIMI}=$ thrombolysis in myocardial infarction.

a Classification by Mori et al. ${ }^{15}$

territory and is a predictor of recanalization after ERT. ${ }^{18}$ The interrelationship between revascularization and the extent of collateral supply is likely to be important, but it is not as well studied.

American Society of Intervention and Therapeutic Neuroradiology/Society of Interventional Radiology Collateral Flow Grading Scale. In addition to proposing the TICI scale for stroke trial design and report- ing standards, Higashida et al. described the importance of collateral flow and proposed an adjunctive Collateral Flow Grading System. This scale grades collateral supply from 0 to 4 , characterizing collateral flow from absent to complete and rapid (table 2). This collateral scale has been shown to predict infarct growth, ${ }^{19}$ and a more recent study found that baseline collateral scores predict recanalization success. ${ }^{18}$ 


\begin{tabular}{|c|c|c|}
\hline Scale & Advantages & Limitations \\
\hline \multirow[t]{2}{*}{$\begin{array}{l}\text { Thrombolysis in myocardial ischemia } \\
\text { (TIMI) }\end{array}$} & Simple, frequently used & $\begin{array}{l}\text { Not accurate for collateral and } \\
\text { reperfusion }\end{array}$ \\
\hline & & Does not account for eloquency/occlusion site \\
\hline Thrombolysis in cerebral ischemia (TICI) & & $\begin{array}{l}\text { Does not account for eloquency/occlusion } \\
\text { site }\end{array}$ \\
\hline Arterial occlusion lesion (AOL) & Simplest, high interobserver reliability & No reperfusion \\
\hline \multirow[t]{2}{*}{ Qureshi } & Accounts for occlusion site & Complex \\
\hline & & Not precise for reperfusion \\
\hline \multirow[t]{2}{*}{ ASITN/SIR collateral flow grading } & Collateral grading & No recanalization \\
\hline & & No reperfusion \\
\hline
\end{tabular}

Christoforidis pial collateral scale. Christoforidis et al. ${ }^{20}$ described a pial collateral grading scale for proximal MCA occlusions. The scale ranges from 1 to 5 , indicating very good to very poor collaterals. This scale was used in angiograms for a series of patients with AIS and demonstrated lower infarct volume and discharge modified Rankin scale score for those patients with better pial collateral scores.

The Matas test. Wang et al. ${ }^{21}$ first reported on a provocative test of temporary large vessel occlusion to evaluate the adequacy of collateral circulation. This evolved to include clinical assessment, nuclear brain imaging to assess the first-pass effect of an isotope injected during the occlusion and, more recently, estimating the difference in contrast transit time by

\begin{tabular}{|c|c|c|c|}
\hline \multirow[t]{2}{*}{ Table 4} & \multicolumn{3}{|c|}{$\begin{array}{l}\text { Revascularization scale use in } \\
\text { selected endovascular acute } \\
\text { ischemic stroke clinical studies }\end{array}$} \\
\hline & & $\begin{array}{l}\text { Sample } \\
\text { size/no. } \\
\text { of centers }\end{array}$ & $\begin{array}{l}\text { Primary } \\
\text { reperfusion } \\
\text { scale }\end{array}$ \\
\hline \multicolumn{2}{|c|}{ MERCI Pilot25 } & $28 / 7$ & TIMI \\
\hline \multicolumn{2}{|c|}{ MERCI Trial ${ }^{26}$} & $141 / 25$ & TIMI \\
\hline \multicolumn{2}{|c|}{ PROACT Trial ${ }^{27}$} & $40 / 37$ & TIMI \\
\hline \multicolumn{2}{|c|}{ PROACT II Trial28 } & $180 / 54$ & TIMI \\
\hline \multicolumn{2}{|l|}{ IMS I $\left.\right|^{13}$} & $80 / 17$ & $\mathrm{TICl}$ \\
\hline \multicolumn{2}{|l|}{ IMS II29 } & $72 / 13$ & $\mathrm{TICl}$ \\
\hline \multicolumn{2}{|l|}{ IMS III'30 } & $\begin{array}{l}900 / 60 \\
\text { (planned) }\end{array}$ & $\mathrm{AOL}, \mathrm{TICl}$ \\
\hline \multicolumn{2}{|c|}{ Penumbra ${ }^{31}$} & $30 / 6$ & TIMI \\
\hline \multicolumn{2}{|c|}{$\begin{array}{l}\text { Penumbra Pivotal } \\
\text { Stroke Trial }^{32}\end{array}$} & $125 / 24$ & TIMI \\
\hline \multicolumn{2}{|c|}{ Qureshi et al. study ${ }^{16}$} & $15 / 1$ & Qureshi \\
\hline
\end{tabular}

injecting the contralateral vessel with poor collateral, indicated by a delay of more than 2 seconds.

Thrombolysis in brain ischemia scale. Application to noninvasive imaging of the optimal scale would provide wider application to AIS trials, beyond endovascular therapy, or provide application for reocclusion monitoring following interventional therapy. The thrombolysis in brain ischemia (TIBI) scale correlates with initial stroke severity and clinical improvement post-thrombolysis and is now in use in AIS clinical trials of sonothrombolysis. ${ }^{22,23}$ The TIBI scale is composed of 5 points; 0 indicates absence of flow signals, and 5 indicates a less than $30 \%$ difference from control in the mean blood flow velocity (table 2).

COMMENT Applying a simple grading scale to a complex disease is challenging. There are numerous difficulties encountered in revascularization grading of arterial occlusions. Ischemic stroke is a complex and heterogeneous disease that includes varying sizes of arterial occlusions (from proximal to distal), with varying territories in individual patients, varying baseline neuroanatomy of collateral supply, and varying functional collateralization. Furthermore, the specific tissue "eloquence" of the affected vascular territory will dramatically affect clinical outcomes. Less attention has been given to the role of cerebral collateral circulation in revascularization studies. The presence of collateral circulation may have a considerable prognostic role. Collateral grading is often challenging because of the need for very complex characterizations to eliminate subjectivity. Performing angiography of the neighboring vascular territory is necessary to describe this collateral flow. Finally, 
angiographic observation of early venous shunting in intra-arterial reperfusion therapy is predictive of hemorrhage, which is not accounted for in the current scales. ${ }^{24}$

Many unanswered questions remain about current grading systems, including their inter-rater reliability, their individual and relative prognostic value for clinical outcomes, and their association with each other.

Grading scales that measure recanalization or angiographic reperfusion are likely to be comparable in predictive ability; however, they should not be used interchangeably, because they measure properties of arterial revascularization that are potentially exclusive of each other. Different therapies may affect recanalization and reperfusion differently, and therefore consistent use of the same grading scale may be necessary. For example, the reperfusion grade, as opposed to the recanalization grade measured by the AOL scale, may be less important when using thrombolytics that could lyse small distal emboli. Angiographic reperfusion may be more relevant for mechanical thrombectomy without systemic thrombolysis, in which case small distal emboli may be more likely to persist.

Comparison between the AIS revascularization scales discussed above, with pros and cons, is shown in table 3. The TICI and TIMI are the scales most commonly used in AIS trials; table 4 outlines the various revascularization scales used in selected AIS studies. Future gathering of expert opinion and consensus on revascularization grading are needed, along with more data on inter-rater/intra-rater and scale agreement.

\section{AUTHOR CONTRIBUTIONS}

Dr. Zaidat: drafting/revising the manuscript, study concept or design, study supervision. Dr. Lazzaro: drafting/revising the manuscript, study concept or design, analysis or interpretation of data. Dr. Liebeskind: drafting/revising the manuscript, acquisition of data. Dr. Janjua: drafting/ revising the manuscript, study concept or design. Dr. Wechsler: drafting/ revising the manuscript, contribution of vital reagents/tools/patients, acquisition of data. Dr. Nogueira: study concept or design, analysis or interpretation of data. Dr. Edgell: drafting/revising the manuscript, analysis or interpretation of data. Dr. Kalia: drafting/revising the manuscript. Dr. Badruddin: drafting/revising the manuscript, contribution of vital reagents/tools/patients. Dr. English: drafting/revising the manuscript, study concept or design, analysis or interpretation of data, contribution of vital reagents/tools/patients, acquisition of data, statistical analysis, study supervision, obtaining funding. Dr. Yavagal: drafting/revising the manuscript. Dr. Kirmani: drafting/revising the manuscript, study concept or design, analysis or interpretation of data. Dr. Alexandrov: drafting/ revising the manuscript, acquisition of data. Dr. Khatri: study concept or design, study supervision.

\section{DISCLOSURE}

Dr. Zaidat serves on the scientific advisory board for Talecris; served on the adjudication committee for Stryker; received speaker honoraria from Stryker; served on the editorial board of Frontiers in Neurology (Endovascular \& Interventional Neurology Section); serves as Editor of The Journal of Neurointerventional Surgery; serves as Associate Editor and is a member of the Editorial Board of Journal of Stroke \& Cerebrovascular Diseases; served as a consultant for Stryker Neurovascular, Codman Neurovascular, Microvention Inc; and has received research support from Society of Vascular \& Interventional Neurology (SVIN) for this educational activity. Dr. Lazzaro reports no disclosures. Dr. Liebeskind served as a consultant for Concentric Medical and CoAxia and receives research support from NIH. Dr. Janjua serves on the scientific advisory board for Lundbeck/ DSMB and Neurointerventions; receives research support from NIH/ NINDS; and holds stock or stock options or Board of Directors Compensation for Neurointerventions. Dr. Wechsler reports no disclosure. Dr. Nogueira serves as a consultant for Concentric and Coaxia. Dr. Edgell serves as a member of the data safety monitoring board for the Medtronic INPACT SFT clinical trial and Medtronic ACTIVE clinical trial; serves as a member of the Clinical Events Committee, Concentric TREVO-2 clinical trial; and serves as an editorial board member for The Neurohospitalist. Dr. Kalia has received funding for travel or speaker honoraria from Penumbra Inc. for consultation and speaking over the past 2 years; serves as Associate Editor for Frontiers in Endovascular Neurology; served as a consultant to Penumbra Inc, Codman Neurovascular, Micrus Inc, Genentech, and Boston Scientific; received research support from the Florida Biomedical New Investigator Award; and received an intramural grant. Dr. Badruddin received funding for travel and speaker honoraria for the SVIN conference and to attend the SVIN roundtable summit. Dr. English served on the scientific advisory boards for Concentric Medical Inc.; served as a medical advisory board member of Co-Aaxia Inc. and eV 3 Inc.; served as an Associate Editor for Journal of Neuroimaging; was employed by Concentric Medical Inc. in 2008-2009, Co-Aaxia Inc. in 2008, and eV 3 Inc. in 2008; and has acted as an expert witness. Dr. Yavagal received an honorarium from Penumbra Inc. for consultation and speaking; serves as an Associate Editor for Frontiers in Endovascular Neurology; and serves as a consultant to Penumbra Inc., Codman Neurovascular, Micrus Inc., Genentech, and Boston Scientific. Dr. Kirmani served on the advisory board for Otsuka Pharmaceuticals; served as an Associate Editor for Frontiers in Clinical Trials in Neurology; received publishing royalties from Taylor and Francis Group for The Stroke Center Handbook; receives research support from Penumbra, Inc., and Genentech, Inc.; received research support from NIH/NINDS; and has served as expert witness for stroke cases. Dr. Alexandrov serves as an Associate Editor for Frontiers of Interventional Neurology. Dr. Khatri is on the Executive Committee of the IMS III Trial; is the Neurology PI of the Penumbra THERAPY Trial; has received research support from Genentech, Inc., for survey implementation; and served on the editorial boards of Frontiers in Endovascular and Interventional Neurology. Go to Neurology.org for full disclosures.

Received July 10, 2011. Accepted in final form October 26, 2011.

\section{REFERENCES}

1. The National Institute of Neurological Disorders and Stroke rt-PA Stroke Study Group. 0 Tissue plasminogen activator for acute ischemic stroke. N Engl J Med 1995; 333:1581-1587.

2. Zaidat OO, Suarez JI, Sunshine JL, et al. Thrombolytic therapy of acute ischemic stroke: correlation of angiographic recanalization with clinical outcome. AJNR Am J Neuroradiol 2005;26:880-884.

3. von Kummer R, Holle R, Rosin L, Forsting M, Hacke W. Does arterial recanalization improve clinical outcome in carotid territory stroke? Stroke 1995;26:581-587.

4. Nogueira RG, Liebeskind DS, Sung G, Duckwiler G, Smith WS, MERCI and Multi MERCI Writing Committee. Predictors of good clinical outcomes, mortality, and successful revascularization in patients with acute ischemic stroke undergoing thrombectomy: pooled analysis of the Mechanical Embolus Removal in Cerebral Ischemia (MERCI) and Multi MERCI Trials. Stroke 2009;40: 3777-3783. 
5. Rha JH, Saver JL. The impact of recanalization on ischemic stroke outcome. Stroke 2007;38:967-973.

6. Baker WL, Colby JA, Tongbram V, et al. Neurothrombectomy devices for the treatment of acute ischemic stroke: state of the evidence. Ann Intern Med 2011;154:243-252.

7. Khatri P, Abruzzo T, Yeatts SD, Nichols C, Broderick JP, Tomsick TA, IMS I and II Investigators. Good clinical outcome after ischemic stroke with successful revascularization is time-dependent. Neurology 2009;73:1066-1072.

8. Saver JL, Liebeskind DS, Noguiera RG, Jehan R. Need to clarify Thrombolysis in Myocardial Ischemia (TIMI) scale scoring method in the Penumbra Pivotal Stroke Trial. Stroke 2010;41:e115-e116.

9. Tomsick T. TIMI, TIBI, TICI: I came, I saw, I got confused. AJNR Am J Neuroradiol 2007;28:382-384.

10. TIMI Study Group. The Thrombolysis in Myocardial Infarction (TIMI) Trial: phase I findings. N Engl J Med 1985;312:932-936.

11. Chesebro JH, Knatterud G, Roberts R, et al. Thrombolysis in Myocardial Infarction (TIMI) Trial, Phase I: a comparison between IV tPA and IV streptokinase. Circulation 1987;76:142-154.

12. Cannon CP, Braunwald E, McCabe CH, Antman EM. The Thrombolysis in Myocardial Infarction (TIMI) trials: the first decade. J Interv Cardiol 1995;8:117-135.

13. Khatri P, Neff J, Broderick JP, Khoury JC, Carrozzella J, Tomsick T. Revascularization end points in stroke interventional trials: recanalization versus reperfusion in IMS-I. Stroke 2005;36:2400-2403.

14. Arnold M, Nedeltchev K, Remonda L, et al. Recanalisation of middle cerebral artery occlusion after intra-arterial thrombolysis: different recanalisation grading systems and clinical functional outcome. J Neurol Neurosurg Psychiatry 2005;76:1373-1376.

15. Mori E, Yoneda Y, Tabuchi M, et al. Intravenous recombinant tissue plasminogen activator in acute carotid artery territory stroke. Neurology 1992;42:976-982.

16. Qureshi AI. New grading system for angiographic evaluation of arterial occlusions and recanalization response to intra-arterial thrombolysis in acute ischemic stroke. Neurosurgery 2002;50:1405-1414, discussion 1414-1415.

17. Higashida RT, Furlan AJ, Roberts $\mathrm{H}$, et al. Trial design and reporting standards for intra-arterial cerebral thrombolysis for acute ischemic stroke. Stroke 2003;34:e109-e137.

18. Bang OY, Saver JL, Kim SJ, et al. Collateral flow predicts response to endovascular therapy for acute ischemic stroke. Stroke Epub 2011 Jan 13.

19. Bang OY, Saver JL, Buck BH, et al; UCLA Collateral Investigators. Impact of collateral flow on tissue fate in acute ischaemic stroke. J Neurol Neurosurg Psychiatry 2008;79: 625-629.
20. Christoforidis GA, Mohammad Y, Kehagias D, Avutu B, Slivka AP. Angiographic assessment of pial collaterals as a prognostic indicator following intra-arterial thrombolysis for acute ischemic stroke. AJNR Am J Neuroradiol 2005; 26:1789-1797.

21. Wang H, Lanzino G, Kraus RR, Fraser KW. Provocative test occlusion or the Matas test: who was Rudolph Matas? J Neurosurg 2003;98:926-928.

22. Demchuk AM, Burgin WS, Christou I, et al. Thrombolysis in brain ischemia (TIBI) transcranial Doppler flow grades predict clinical severity, early recovery, and mortality in patients treated with intravenous tissue plasminogen activator. Stroke 2001;32:89-93.

23. Alexandrov AV, Demchuk AM, Wein TH, Grotta JC. Yield of transcranial Doppler in acute cerebral ischemia. Stroke 1999;30:1604-1609.

24. Ohta H, Nakano S, Yokogami K, Iseda T, Yoneyama T, Wakisaka S. Appearance of early venous filling during intra-arterial reperfusion therapy for acute middle cerebral artery occlusion: a predictive sign for hemorrhagic complications. Stroke 2004;35:893-898.

25. Gobin YP, Starkman S, Duckwiler GR, et al. MERCI 1: a phase 1 study of mechanical embolus removal in cerebral ischemia. Stroke 2004;35:2848-2853.

26. Smith WS. Safety of mechanical thrombectomy and intravenous tissue plasminogen activator in acute ischemic stroke: results of the Multi Mechanical Embolus Removal in Cerebral Ischemia (MERCI) Trial, part I. AJNR Am J Neuroradiol 2006;27:1177-1182.

27. Del Zoppo GJ, Levy D, Broderick JP. Thrombolytic therapy in the treatment of stroke. Drugs 1997;54(suppl 3): 90-99.

28. Furlan A, Higashida R, Wechsler L, et al. Intra-arterial prourokinase for acute ischemic stroke. The PROACT II Study: a randomized controlled trial. JAMA 1999;282: 2003-2011.

29. The IMS Investigators. The Interventional Management of Stroke (IMS) II Study. Stroke 2007:38:21272135.

30. Khatri P, Hill MD, Palesch YY, et al. Methodology of the Interventional Management of Stroke III Trial. Int J Stroke 2008;3:130-137.

31. Bose A, Henkes H, Alfke K, et al. The Penumbra System: a mechanical device for the treatment of acute stroke due to thromboembolism. AJNR Am J Neuroradiol 2008;29: 1409.

32. The Penumbra Pivotal Stroke Trial Investigators. The Penumbra Pivotal Stroke Trial: safety and effectiveness of a new generation of mechanical devices for clot removal in intracranial large vessel occlusive disease. Stroke 2009:40: 2761-2768. 


\section{Neurology}

\section{Revascularization grading in endovascular acute ischemic stroke therapy O.O. Zaidat, M.A. Lazzaro, D.S. Liebeskind, et al. Neurology 2012;79;S110-S116 \\ DOI 10.1212/WNL.0b013e3182695916}

This information is current as of September 24, 2012

\section{Updated Information \& Services}

References

Citations

Subspecialty Collections

Permissions \& Licensing

Reprints including high resolution figures, can be found at: http://n.neurology.org/content/79/13_Supplement_1/S110.full

This article cites 31 articles, 18 of which you can access for free at: http://n.neurology.org/content/79/13_Supplement_1/S110.full\#ref-list1

This article has been cited by 1 HighWire-hosted articles: http://n.neurology.org/content/79/13_Supplement_1/S110.full\#\#otherar ticles

This article, along with others on similar topics, appears in the following collection(s):

All Cerebrovascular disease/Stroke

http://n.neurology.org/cgi/collection/all_cerebrovascular_disease_strok e

All Imaging

http://n.neurology.org/cgi/collection/all_imaging

Information about reproducing this article in parts (figures,tables) or in its entirety can be found online at:

http://www.neurology.org/about/about_the_journal\#permissions

Information about ordering reprints can be found online:

http://n.neurology.org/subscribers/advertise

Neurology ${ }^{\circledR}$ is the official journal of the American Academy of Neurology. Published continuously since 1951, it is now a weekly with 48 issues per year. Copyright Copyright (? 2012 by AAN Enterprises, Inc.. All rights reserved. Print ISSN: 0028-3878. Online ISSN: 1526-632X.

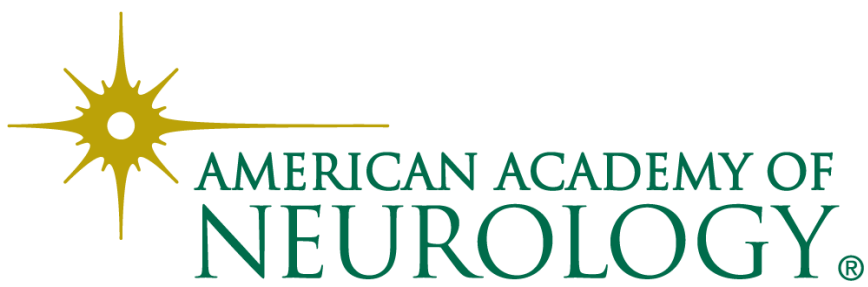

